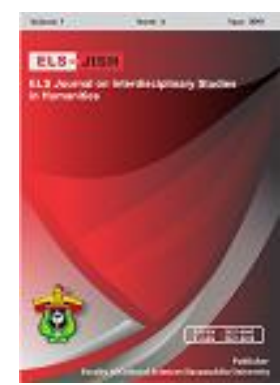

ELS-JISH

ELS Journal on Interdisciplinary Studies on Humanities

Volume 2 Issue 3, 2019

ISSN (print) : 2621-0843

ISSN (online) : 2621-0835

Homepage : http://journal.unhas.ac.id/index.php/jish

\title{
The Modality Systems in Lawyer and Witness's Utterances on Courtroom Questioning of Legal Discourse
}

\author{
Reski Ramadhani ${ }^{1}$, Rosaria Mita Amalia ${ }^{2}$, Lia Maulia Indrayani ${ }^{3}$, Sutiono Mahdi ${ }^{4}$ \\ 1 reskidhani95@gmail.com
}

\begin{abstract}
The use of Systemic Functional Linguistics proposed by Halliday and Matthiessen (2004) is rarely applied mostly in courtroom discourse analysis. This article presents the analysis of modality system used in the lawyer and witness's utterances on courtroom questioning in cross-examination. The main focus is to explore the lawyer's linguistic power to examine the facts given by the witness. Applying the interpersonal grammatical metaphor, the utterances are evaluated based on the different types, orientations, and values of modality in order to show a powerful position and to convince the jury toward the facts. This is a case study employed a qualitative method with a descriptive approach. The data are taken from the transcriptions of the courtroom questioning between the lawyer and the witness of Michigan V Charles Warren's case from YouTube (2015). This case study revealed that most of the utterances produced by the lawyer contain higher and more medium value of modality system. Then, the way he states the argument tends to be more objective. On the other hand, the witness tends to use medium and low modality system. In answering the questions, subjectivity is employed more by the witness which indicates that he has a personal attitude toward the state of affairs. It can be indicated that the lawyer has more linguistic power by applying more high value of modality system which means that he makes the facts strongly clearer toward the state of affairs at the time. The implication of this research is expected to give the information to the reader on how language can provide power to the user especially for the lawyer in order to examine the facts given by the witness
\end{abstract}

Keywords: Modality, Orientation, Types, Value, Courtroom Questioning

How to cite: Ramadhani, R., et al. (2019). The Modality Systems in Lawyer and Witness's Utterances on Courtroom Questioning of Legal Discourse. ELS Journal on Interdisciplinary Studies in Humanities, 2 (3), 378-388

\section{Introduction}

This study focuses on cross-examination questioning forms of legal discourse used by lawyers to modify the answers provided by witnesses. Lawyer-witness examination is the most essential part of courtroom discourse analysis. In this process, lawyers usually have a strategy to provide discursive questions as function to coercive or to provide pressure to the witnesses in asserting what they do not actually aim to say and the result of the evidence may be twisted and altered for

\footnotetext{
${ }^{1,2,3,4}$ Universitas Padjajaran, Indonesia 
social injustice (Gibbons \& Turell, 2008). In addition, lawyers also use the methods which are acceptable to ask questions that lead negative impact for the confidence of the witness that may result in less accuracy of the answers of the witnesses (Oxburgh, Myklebust, \& Grant, 2010). The court is the place whereby both opposite sides compete to gain power especially in front of the jury. Dong, (2013) argues that cross-examination has two main purposes which are to gain the fact and to create a destructive cross. It means that the witness may obtain some trap questions which minimize the testimony given by them or even the testimony will be disregarded during the court.

The role of linguists as expert witnesses in both civil and criminal trials cannot be avoidable. Linguist expertise can obviously help the judge or jury to provide a decision in the courtroom (Tiersma \& Solan, 2002). Furthermore, Dong (2013) argues that linguists are occurring as one of the most important elements of the courts in this development of low science because legal actions must be related to the human's thought and how the language is transmitted through it. In addition, linguists are allowed to testify the comprehensibility of legal documents and statutes, juror's ability to comprehend the instructions, the variety of dialect use, the detection of lying, the identification of authors and speakers, cross-examination between lawyer and witness, and so on (Tiersma \& Solan, 2002). Moreover, some of the courtroom discourses involved in the legal action are the opening and closing of the statements and arguments, testimony, cross-examination questioning, and so on.

Relying on this phenomenon, the involving subjects in linguistics used to investigate the linguistic evidence in legal discourse are such as Phonetics, Semantic, Pragmatic, Psycholinguistics, Sociolinguistics, Rhetoric, Systemic Functional Linguistics, Critical Discourse Analysis and Graphology (Tiersma \& Solan, 2002; Dong, 2013). Meanwhile, this study uses the systemic functional linguistic approach proposed by Halliday and Matthiessen (2004). The perspective which is applied is interpersonal grammatical metaphor mainly modality system. This approach can be used to investigate the power showed in the cross-examination questioning especially the lawyers. As Dong (2013) states that "linguistic power can be defined as different social positions in the certain context of the situation, which is mainly realized by means of controlling or losing control of language and modality system are the grammatical means to control or lose control of language". This approach is implemented because it is still rarely touched as courtroom discourse analysis.

Systemic Functional Linguistics (SFL), some linguists also call it a Systemic Functional Approach (SFA) or Systemic Approach, is defined as selecting theory. According to Halliday \& Matthiessen (2004), language is a 'system of meaning'. In addition, Gerot \& Wignell (1994) states that functional grammar is 'a resource for making meaning. The grammar in systemic functional attempt to express the language based on the actual use which is also focused on texts and their contexts. When people use languages, their language acts are the expression of meaning. Moreover, grammar is considered as a making-meaning activity through the selected words (Bloor \& Bloor, 2004)

Halliday and Matthiessen (2004) also state that language is realized into three metafunctions: (1) ideational meaning; (2) interpersonal meaning; and (3) textual meaning. The interpersonal metafunction is the main focus of this study which is 
concerned with the interpersonal relationship between speaker and listener or reader and writer. As Thompson (2013) argues that interpersonal meaning does not only allow people to make relation with other people but also how the relationship is maintained and it also expresses people's point of view about the world which influences their behavior. However, the primary concern of this research does not only see the interpersonal meaning as congruent form but also see based on the metaphorical form which is known as interpersonal grammatical metaphor.

The grammatical metaphor which is proposed by Halliday \& Matthiessen (2004) is the metaphorical concept of grammar. As Halliday \& Webster (2009) argue that grammatical metaphor explains "the junction of category meanings, not simply word meanings". Furthermore, Eggins (2004) states that the grammatical metaphor realizes meaning from the typically congruent form into non-congruent (metaphorical) form. Halliday \& Matthiessen (2004)) divide two basic kinds of grammatical metaphors which relate to in term of metafunctional model of meaning, interpersonal and ideational grammatical metaphor. The first term is the main focus of this study. Liu (2016) states that the interpersonal metaphor is differentiated into a metaphor of mood and metaphors of modality. However, the metaphor of the modality system is the part discussed here.

Halliday and Matthiessen (2004) argues that modality focuses on the meaning which lies between positive and negative polarity. Modality system as the speaker's assessment is categorized into modalization (probability and usuality) and modulation (obligation and inclination). In addition, they classified three basic values as modal judgment: high, median, and low. Then, in order to organize the message, people can communicate it by choosing the orientation of modality which can be subjective or objective and the message may be realized into explicit and implicit. Furthermore, the modality system can be used to examine the subjective attitude or willingness of the interlocutors or the objective existence to show the probability or inevitability of the message. Besides, the message can be conveyed as explicit or implicit and this shows that the forms are probably made as subjective implicit, subjective explicit, objective implicit and objective explicit. If the speakers directly highlight their point of view about something, they may choose the subjective explicit. On the other hand, if the speakers indirectly try to say their intention of something, they use the objective implicit form. According to Halliday \& Matthiessen (2004), the subjective and objective implicit forms belong to the metaphorical form of interpersonal meaning. The explanations above can be classified in the following figure:

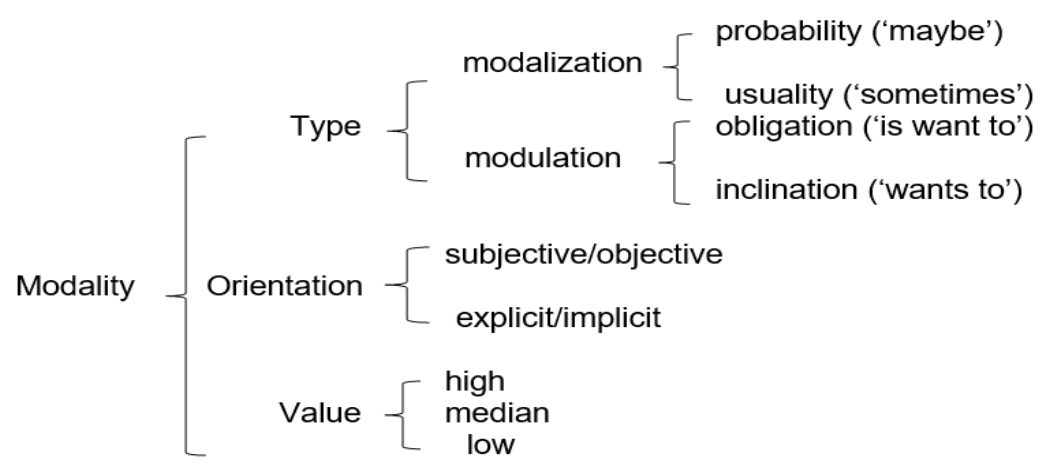

Figure 1. System of types of modality 
In order to modify the message between both speaker and listener or reader and writer, they can select the type, value, and orientation of the modality system. By selecting this system, it can help them to communicate the message more successful. Therefore, because this modality system assesses how the speakers interact with one another, it can be used as the concept for analyzing the speaker's attitude in the courtroom discourse (Dong, 2013). Thus, the theoretical framework of Halliday and Matthiessen (2004) above is applied in this study in determining the modality system used by the lawyer in his utterances during the questioning process of legal discourse.

Regarding this issue, some previous researches are taken in order to provide the research comparison and the gaps which can be filled. First, the study made by Zhenhua (2004) showed that the objectivity used by the lawyer in the crossexamination process displays a more powerful position in front of the jury which determines the successful result. Second, Dong (2013) conducted the similar research and the result showed that there is a different use of modality system between lawyer and witness, then the lawyer is more careful in selecting the words as questions. Last, Catoto (2017) also conducted similar topics but using a different approach and the result showed that there are some maxims which are violated by the witness which indicates the power of the lawyers in conquering the court. Last, However, there are some different points which are conducted by this study. First, this study examines the questioning forms used by the lawyers and the answers provided by the witnesses by using a different approach. Then, this study focuses on the modality system to investigate the case. Therefore, this research is expected to provide the information especially how the lawyers weaken the facts provided by the witnesses in order to obtain more powerful position in front of the jury as the result to conquer the case and may provide an injustice result.

\section{Method}

The data of this study are taken from the transcriptions of cross-examination in Michigan V Charles Warren's Case (2015). This case is a crush which was happening between truck driver and police and it caused the police was dead. The video recordings are downloaded from YouTube. Furthermore, it is unnecessary to obtain permission because it has legally allowed people to consume it. This case is interesting to be taken because at the end of the court the jury decides that the suspect is innocent. In this case, the writer focuses on the linguistic power used by the lawyer by implementing modality system to weaken the testimony or the fact provided by the witnesses. The transcriptions are read thoroughly to identify the modality in lawyer and witnesses' utterances. Then, the data are classified and analyzed based on the types, orientation, and values of the modality system as the downgrading techniques of Halliday \& Matthiessen (2004). The results are also described as congruent and metaphorical forms.

This study uses qualitative research with a case study. Creswell (2012) states that qualitative research is a good way to address a research problem in which you do not know the variables and need to explore. In addition, According to Saldana (2011), qualitative research is an umbrella term for a wide variety of approaches to and methods for the of natural social life. Qualitative research does not use statistical data or numbering in analyzing the data. Qualitative research concerns the quality of the data and refers to the process of data in which this process cannot be analyzed 
or measured by using an experiment. The qualitative research also concerns the nature of the reality of the data, social relationship between the researcher and the object of the research. On this case, the qualitative research is used to analyze and describe the types, the orientation, and the values of the modality system used by the lawyer and witness in their utterances during cross-examination.

\section{The Analysis or Results}

In this part, three samples are presented which is classified based on different types, orientations, and values in order to show how the lawyer uses the successful tactics in examining the witness as result the jury will consider that the witnesses' testimony is incredible.

\subsection{Analysis of Datum One}

Lawyers have many tactics to distract the testimony given by the witnesses such as engaging the witnesses to make speculation to weaken the testimony or even successfully disgracing the witnesses' point of view so that it will not be obvious. The challenge for the witnesses during the courtroom questioning is their ability to convince or to observe the fact of the events which exist. In this case, the event which was happening really fast and surprisingly and it influences their phycology. The impact of this situation will probably make the testimony less accurate and it also influences the jury's decision.

In the example below, it shows how the tactics used by the lawyer to examine the question in order to weaken the assertion of the witness. Table 1 and 2 below classified the utterances provided by the lawyer and witnesses by using modality approach which is differentiated between metaphorical modalities and nonmetaphorical modalities.

Table 1. Modality Analysis of the Lawyer's Utterances

\begin{tabular}{|c|c|c|c|}
\hline No & Utterances & Metaphorical Modality & Non-Metaphorical Modality \\
\hline 1 & $\begin{array}{l}\text { You have to almost look to your } \\
\text { right because you know... }\end{array}$ & & $\begin{array}{l}\text { Have to: proposition } \\
\text { Obligation: high value }\end{array}$ \\
\hline 2 & $\begin{array}{l}\text { You would drive about the } \\
\text { season. }\end{array}$ & & $\begin{array}{l}\text { Would: proposition } \\
\text { Probability: median value }\end{array}$ \\
\hline 3 & $\begin{array}{l}\text { You're absolutely certain that } \\
\text { there were no other cars between } \\
\text { you and the trailer. }\end{array}$ & & $\begin{array}{l}\text { certain: proposition } \\
\text { Probability: high value }\end{array}$ \\
\hline 4 & $\begin{array}{l}\text { You weren't saying screw } \\
\text { everybody else l'll drive as fast as } \\
\text { they want with... }\end{array}$ & & $\begin{array}{l}\text { Will: proposition } \\
\text { Inclination: medium value }\end{array}$ \\
\hline
\end{tabular}

Table 2. Modality Analysis of the Witnesses' Utterances

\begin{tabular}{llll}
\hline No & Utterances & Metaphorical Modality & Non-Metaphorical Modality \\
\hline 1 & $\begin{array}{l}\text { That would be the sort of } \\
\text { hindsight analysis 20/20 people } \\
\text { use... }\end{array}$ & $\begin{array}{l}\text { Would: proposition } \\
\text { Probability: median value }\end{array}$ \\
\hline 2 & $\begin{array}{l}\text { I believe that my thought was } \\
\text { exactly that. }\end{array}$ & $\begin{array}{l}\text { I believe: subjective } \\
\text { Low value }\end{array}$ & \\
\hline 3 & $\begin{array}{l}\text { I'm not sure exactly which one } \\
\text { I've had to stop }\end{array}$ & $\begin{array}{l}\text { I'm not sure: subjective } \\
\text { Low value }\end{array}$ & \\
\hline 4 & $\begin{array}{l}\text {... couldn't make out the color of } \\
\text { what was dragging... }\end{array}$ & $\begin{array}{l}\text { Could: proposition } \\
\text { Probability: low value }\end{array}$ \\
\hline
\end{tabular}


If table 1 and 2 are compared, it is easy for us to find a different modality system used by the lawyer and the witnesses, as the following table 3 below shows:

Table 3. Statistic Result of Modality Analysis of the Lawyer and Witnesses' Utterances

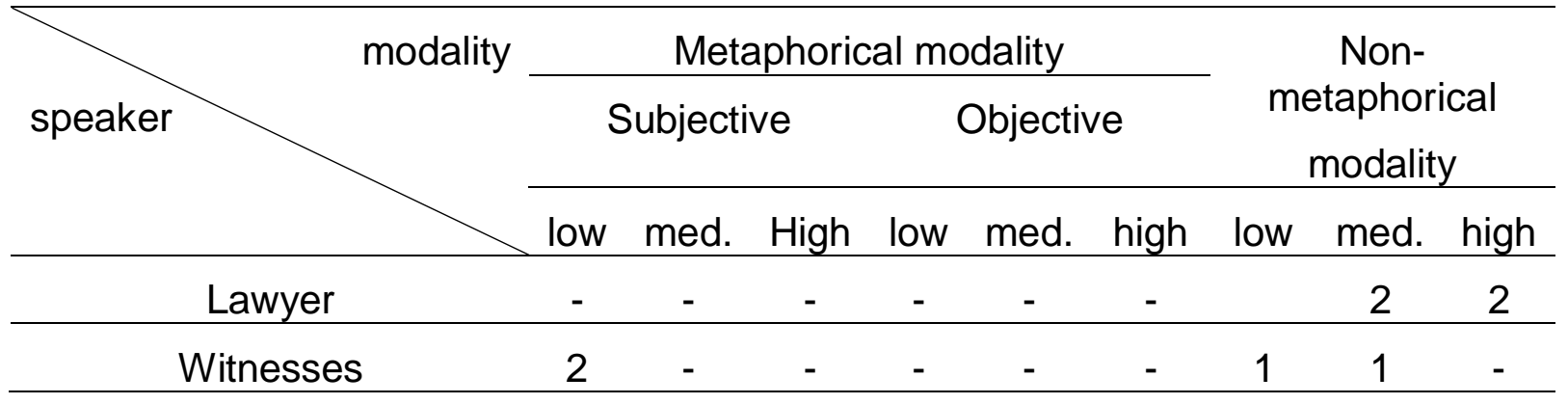

\section{a. Metaphorical Modality System}

Based on the theory explained above, in modality system, if the speakers select more objective modalities, that means that they totally use the fact based on the situation that has been observed or show the fact clearly, and they do not directly take the responsible what they deliver. On the other hand, if the utterances of the speaker contain more subjective arguments, those indicate that the speaker has obviously attitude toward the facts or he or she is willing to take responsibility. From table 1 and 2 above, it shows that, during the cross-examination, the lawyer does not employ the metaphorical modality. On the other hand, metaphorical modality is applied twice by the witness and the modality is objective with low value. From the data, it can be concluded that the witness is are more subjective than the lawyer and he has a personal attitude toward the argument.

\section{b. Non-metaphorical Modality System}

If the metaphorical modality is indicated the subjectivity or objectivity of the speaker, non-metaphorical modality is determined by different values which are conducted by the speakers. It is because different values will have different meanings. If the speakers conduct or provide a certain argument toward the situation, they will have more power in the conversation. This means that the speakers employ a high value of modality. On the other hand, a low value of modality leads to the speakers' uncertainty toward the facts or situation that makes the speakers' position is less powerful or inferior. Based on table 1 and 2 above, it shows that all of the utterances conducted by the lawyer indicate as non-metaphorical modality system. Two of them are high value and the rest of the utterances are medium value. However, the witness uses non-metaphorical modality two times that one is medium value and one is a low value of modality. From the different values of modality system employed by the lawyer and the witness above, it can be concluded that the lawyer is more certain toward the situation compared to the witness who is doubt toward the state of affairs. Therefore, from the analysis above, it shows that the lawyer certainly has a more powerful position than the witness. In conclusion, the witness was not really sure about the situation happening during the crash when answering the question given by the lawyer. 


\subsection{Analysis of Datum Two}

In sample two, the lawyer also provides the questions regarding space or location on the street when the crash was happening quickly and unexpectedly. It also shows that the response provided by the witness less accurate. The analysis will be presented in table 4 and 5 below:

Table 4. Modality Analysis of the Lawyer's Utterances

\begin{tabular}{|c|c|c|c|}
\hline No & Utterances & Metaphorical Modality & Non-Metaphorical Modality \\
\hline 1 & $\begin{array}{l}\text {...what a bit faster than that at } \\
\text { one point and certainly faster } \\
\text { than that. }\end{array}$ & & $\begin{array}{l}\text { certainly: proposition } \\
\text { Probability: high value }\end{array}$ \\
\hline 2 & $\begin{array}{l}\text { You saw the sparks were } \\
\text { definitely coming from } \\
\text { underneath around... }\end{array}$ & & $\begin{array}{l}\text { Definitely: proposition } \\
\text { Probability: high value }\end{array}$ \\
\hline 3 & $\begin{array}{l}\text { You would get there it's a rest } \\
\text { area sign. }\end{array}$ & & $\begin{array}{l}\text { Would: proposition } \\
\text { Probability: median value }\end{array}$ \\
\hline 4 & $\begin{array}{l}\text { You have to almost look to your } \\
\text { right because you know... }\end{array}$ & & $\begin{array}{l}\text { Have to: proposition } \\
\text { Obligation: high value }\end{array}$ \\
\hline \multicolumn{4}{|c|}{ Table 5. Modality Analysis of the Witnesses' Utterances } \\
\hline No & Utterances & Metaphorical Modality & Non-Metaphorical Modality \\
\hline 1 & $\begin{array}{l}\text { No, I'm certain that one no like a } \\
\text { car between us. }\end{array}$ & $\begin{array}{l}\text { I'm certain: subjective } \\
\text { High value }\end{array}$ & \\
\hline 2 & $\begin{array}{l}\text { I think it was a little after that } \\
\text { when he was getting off... }\end{array}$ & $\begin{array}{l}\text { I think: subjective } \\
\text { Low value }\end{array}$ & \\
\hline 3 & Yes, I'm sure. & $\begin{array}{l}\text { I'm sure: subjective } \\
\text { Low value }\end{array}$ & \\
\hline 4 & It was just instinct I guess. & $\begin{array}{l}\text { I guess: subjective } \\
\text { Low value }\end{array}$ & \\
\hline
\end{tabular}

To make the data more obvious, table 6 demonstrates the different statistics of the use of the modality system by the lawyer and the witness.

Table 6. Statistic Result of Modality Analysis of the Lawyer and Witnesses' Utterances

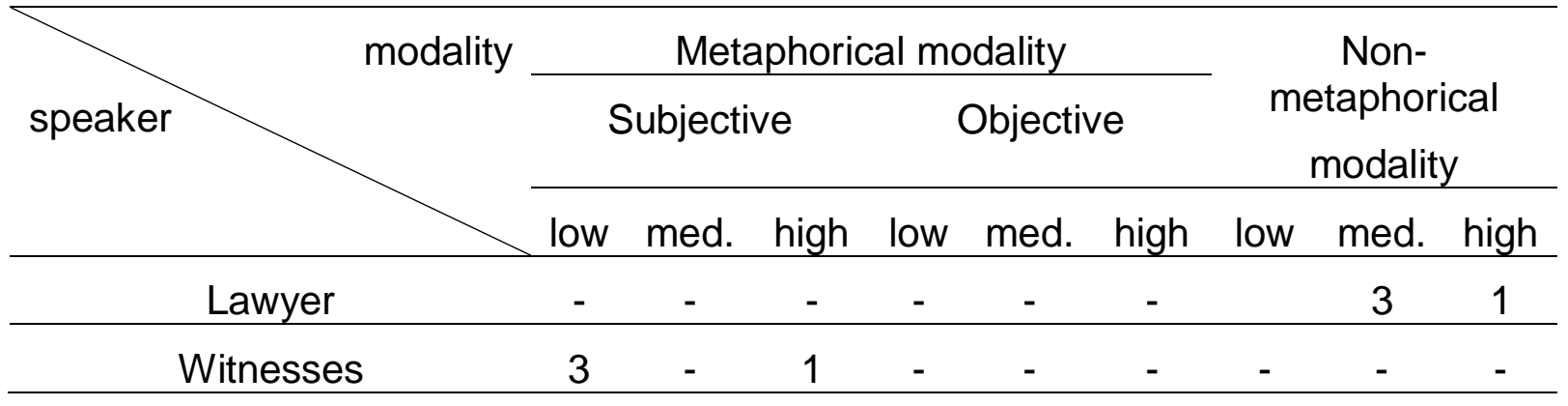

\section{a. Metaphorical Modality System}

Table 6 shows that the lawyer does not employ metaphorical modalities in his utterances. On the other hand, all of the utterances used by the witness use metaphorical modalities which consist of one of high value and three-time is low value. In addition, the witness also tends to choose the subjective modalities toward the situations. It concludes that he uses personal attitude about the fact which leads to the powerless position in front of the jury. Moreover, it also reflects that the witness does not have obvious memory which results in it as inferior respond. 


\section{b. Non-metaphorical Modality System}

In this case, the lawyer uses non-metaphorical modality four times. Three of them employed the high value of modality and the rest is the low value of modality. On the other hand, the witness does not employ the non-metaphorical modality which indicates that he is uncertain about the state of affairs toward the fact in the event. This analysis shows that the lawyer is very careful to select the words which used to examine the witness's testimony. He tries to bring the fact by asking the question as if it is indisputable such as "you have to almost look to your right because you know one getting the wave on the fast track, true?" and the witness replies "Yes, absolutely yes". The lawyer uses the high value of modality "have to" here in order to make the witness admits that it is a truth or to make the witness agree with that. Here, the lawyer has a powerful position because he tries to avoid the subjective engagement and respects to the fact toward the situation which was happening.

To sum up, the lawyer is very successful in examining the witness's testimony because most of the responses provided by the witness contain more subjective or less accurate. The questions provided by the lawyer make the witness uncertainly has a clear memory about the situation. It is matched with the objective of the lawyer in the cross-examination that is to reduce the witness's ability to remember the detailed memory of the facts so that the witness will be less powerful in the conversation.

\subsection{Analysis of Datum Three}

Modality system certainly has the main role to give the power to the lawyer during the cross-examination. Similar with the previous sample, in sample three, the lawyer also employs the strategy to vitiate the witness's ability to provide the proof because the witness cannot illustrate what actually happened when the crash was existing. The witness's ability of communication is really important in this part because to illustrate the event which contains the distance and time, the obvious location, and the directions needs to be clear and logically accepted. The problem is the witness sometimes has a problem in remembering the detail situation and also how to estimate the distance and the time at the moment. In this case, the lawyer has the technique to reduce the witness' ability to remember by using the modality system.

In the sample below, it will show how different modality system used by the lawyer and witness about the details of a collision and the time even the distance and which one will get more powerful position for the jury. The analysis will be presented in table 7 and 8 as follows:

Table 7. Modality Analysis of the Lawyer's Utterances

\begin{tabular}{llll}
\hline No & Utterances & Metaphorical Modality & Non-Metaphorical Modality \\
\hline 1 & $\begin{array}{l}\text { Okay, so normally when you turn } \\
\text { onto the go on to the highway, ... }\end{array}$ & $\begin{array}{l}\text { Normally: proposition } \\
\text { Usuality: medium value }\end{array}$ \\
\hline 2 & $\begin{array}{l}\text { Your memory is little foggy or } \\
\text { uncertain about that? }\end{array}$ & $\begin{array}{l}\text { uncertain: proposition } \\
\text { Probability: high value }\end{array}$ \\
\hline 3 & $\begin{array}{l}\text { You never once indicated to any } \\
\text { of the police officers... }\end{array}$ & $\begin{array}{l}\text { never: proposition } \\
\text { Probability: high value }\end{array}$ \\
\hline 4 & $\begin{array}{l}\text { You believe that the object of the } \\
\text { car that you saw ahead... }\end{array}$ & $\begin{array}{l}\text { You believe: objective } \\
\text { Low value }\end{array}$ & \\
\hline
\end{tabular}


Table 8. Modality Analysis of the Witnesses' Utterances

\begin{tabular}{llll}
\hline No & Utterances & Metaphorical Modality & Non-Metaphorical Modality \\
\hline 1 & $\begin{array}{l}\text { I said previously I assume that } \\
\text { he just wanted to get to... }\end{array}$ & $\begin{array}{l}\text { I assume: subjective } \\
\text { Low value }\end{array}$ & \\
\hline 2 & $\begin{array}{l}\text { Just said possibly something } \\
\text { would come off... }\end{array}$ & & $\begin{array}{l}\text { possibly: proposition } \\
\text { Probability: medium value } \\
\text { Would: proposition } \\
\text { Probability: median value }\end{array}$ \\
\hline 3 & That's possible. & $\begin{array}{l}\text { That's possible: objective: } \\
\text { low value }\end{array}$ & \\
\hline 4 & $\begin{array}{l}\text { I believe I said he was on the } \\
\text { right line... }\end{array}$ & $\begin{array}{l}\text { I believe: subjective } \\
\text { Low value }\end{array}$ & \\
\hline
\end{tabular}

Table 9 below shows the result of the statistic of the modality system of the lawyer and the witness's utterances.

Table 9. Statistic Result of Modality Analysis of the Lawyer and Witnesses'

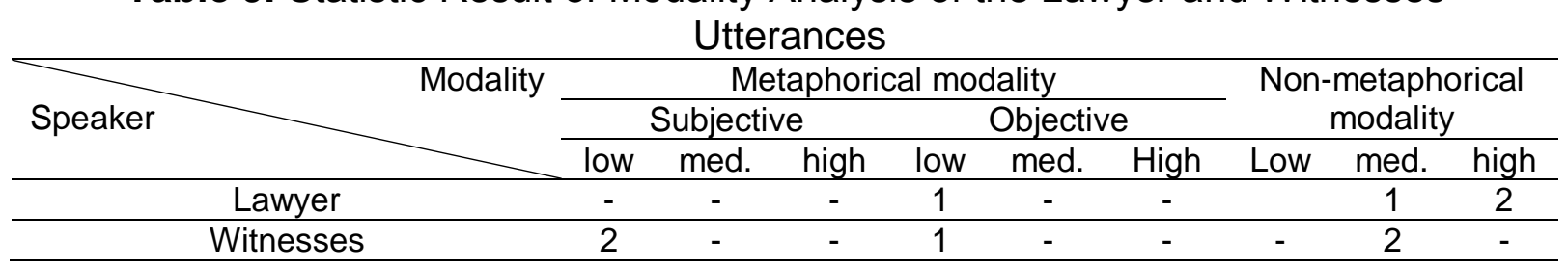

\section{a. Metaphorical Modality System}

Based on table 9, it is easy for us to see the comparison of the metaphorical modality employed by both the lawyer and the witness. Both of them use the metaphorical modality system, but higher percentage belong to the witness. The lawyer uses metaphorical modality one time which low value, but the meaning still shows more objective. That means the lawyer does not want to use his personal attitude toward the state of affairs. He still maintains the facts even though it contains low-value modality. In this case, he certainly has a more powerful statement. Compared to the witness, he chooses the metaphorical three times which contain the low value of modality. Two of three are considered more subjective because he is uncertain about his memory toward the obvious event which was happening. Then one is objective which means he tries to avoid the speculation by indicating what the lawyer believes is possible to happen. When he uses the metaphorical modality 'I believe', 'that's possible' or 'I assume', those indicate that he does not really have a clear memory about the phenomena. As a result, because the witness provides less accurate of the testimony, his statement will be inferior for the jury.

\section{b. Non-metaphorical Modality System}

Form table 9, the lawyer uses non-metaphorical modality three times which two times are high value, one is the median value of modalities, and no one low value of modalities is employed. On the other hand, the witness only uses non-metaphorical two times that are median value of modalities. It concludes that, in the lawyer's statement, he tends to use a more high value of modality which indicates his powerful position. In addition, the lawyer can certainly bring the facts that may disregard the witness's testimony. The lawyer demonstrates the high and the medium value, in this case, to make the witness agree with his statement toward the events and force the witness to admit it as a truth. For instance, when the lawyer provides the question like "so normally when you turn onto the go on to the highway 
and I'll pull up a map here in a second. Let me go onto the highway here, you're merging into the slow thing of the right lane, yes?" and the witness replies "yes'. Here, the lawyer tries to illustrate the possible action which was happening at the moment. In this case, the lawyer tries to make the witness admit that situation by using the modality system 'normally' as if it is the fact which happened when he was in the location. This means that the lawyers try to lead the facts which can make the fact provided by the witness is inferior form the jury.

Based on the explanation above, it is quite easy for us to determine what kind of technique used by the lawyer to weaken the witness's ability during the crossexamination. Most of the statements produced by the lawyers employ the high value of the modality system and the message contain more objective rather than subjective. When the lawyer disregards the testimony from the witness, he obtains a more powerful position in the courtroom because he is certain about the facts that have been observed and it is more reliable for the jury, and vice versa.

\section{Conclusion}

The present study of analyzing the legal discourse of cross-examination between the lawyer and the witness uses the interpersonal grammatical metaphor mainly modality system. The theory of modality system proposed by Halliday \& Matthiessen (2004) is conducted by classifying the different types, orientations, and values. Those systems determine how the speaker get the high power or position for the jury based on the linguistic units which are employed. This study also analyzed the data based on the metaphorical and non-metaphorical forms.

According to the analysis of three samples above, it shows that there are different modality systems used by both lawyer and witness in their utterances. In this case, the lawyer is successfully more careful in asking the questions by choosing the appropriate words. It can be seen that most of the lawyer's utterances contain high value of modality system such as have to, never, certain, should, etc. and some median values of modality such as would, will, etc. In addition, the lawyer also tends to be more objective rather than subjective which indicates that he avoids to use personal attitude toward the fact and he is certain with the facts which were being observed. On the other hand, the witness is likely to employ the median and low values of modality such as possibly, could, can, etc. Furthermore, in metaphorical form, most of the witness's utterances contain more subjective with a low value of modality such as "I think", "I assume", "I believe", and etc. It indicates that the witness has personal engagement toward the fact and he does not have a clear memory or less accurate toward the event which was happening. This concludes that the lawyer has more powerful linguistic position and more persuasive for the jury rather than the witness.

As the implication of this research, it is expected that the lawyer and the witness have to be more careful in selecting the words which are used to question or to answer in courtroom process especially using the modality system in order to get the successful result. It is because different modality systems will give a different impression from the listener or the reader which influence as successful communication. 


\section{Acknowledgments}

We thank our colleagues from Padjadjaran University who provided insight and expertise that greatly assisted the research, although they may not agree with all of the interpretations/conclusions of this paper. We also thanks to the lecturers of Padjadjaran University especially Linguistic Study for comments that greatly improved the manuscript. We would also like to show our gratitude to our other colleagues for sharing their pearls of wisdom with us during the course of this research, and we thank to for the reviewers for their so-called insight.

\section{References}

Bloor, T., \& Bloor, M. (2004). The Functional Analysis of English. London: Arnold.

Catoto, J. S. (2017). On Courtroom Questioning: A Forensic Linguistic Analysis. 33.

Creswell, J. W. (2012). Educational research. Pearson.

Dong, J. (2013). Interpersonal Metaphor in Legal Discourse: Modality in Crossexaminations. Journal of Language Teaching and Research, 4(6). https://doi.org/10.4304/jltr.4.6.1311-1321

Eggins, S. (2004). Introduction to Systemic Functional Linguistics: 2nd Edition. A\&C Black.

Gerot, L., \& Wignell, P. (1994). Making Sense of Functional Grmmar. Sydney: Gerd Stabler.

Gibbons, J., \& Turell, M. T. (2008). Dimensions of Forensic Linguistics. USA: John Bejamins B.V.

Halliday, M. A. K., \& Matthiessen, C. M. I. M. (2004). An introduction to functional grammar (3rd ed). London: New York: Arnold; Distributed in the United States of America by Oxford University Press.

Halliday, M. A. K., \& Webster, J. J. (2009). Bloomsbury Companion to Systemic Functional Linguistics. A\&C Black.

Liu, R. Q. (2016). Schools of Linguistics. Beijing: Foreign Language Teaching and Research Press.

Oxburgh, G. E., Myklebust, T., \& Grant, T. (2010). The question of question types in police interviews: A review of the literature from a psychological and linguistic perspective. International Journal of Speech Language and the Law, 17(1). https://doi.org/10.1558/ijsll.v17i1.45

Saldana, J. (2011). Fundamentals of Qualitative Research. Oxford, New York: Oxford University Press.

Thompson, G. (2013). Introducing Functional Grammar. Routledge.

Tiersma, P. M., \& Solan, L. (2002). The Linguist on the Witness Stand: Forensic Linguistics in American Courts. Language, 78(2), 221-239. https://doi.org/10.1353/lan.2002.0135

Zhenhua, W. (2004). Power in Cross-Examination: An "modality" Analysis of a Segment of Courtroom Discourse of O. J. Simpson Case. 